\title{
9. OF DEFICITS AND OTHER DANGEROUS THINGS...
}

\author{
Presidential Address to AARE, Adelaide, 1 December 1998
}

The time has come, the Walrus said,

To speak of many things:

Of shoes, and ships, and sealing wax,

Of cabbages and kings. (Carroll, 1980)

The theme of this year's conference is 'Research in education: does it count?', so I have decided to take up the matter of deficits. I've been influenced here not only by the conference theme, but also by a number of other matters that have been prominent for me this year. One is the fact that most of the people I know now spend a good deal of their time working out how we are going to bring in some more money for our institution and ourselves. Another is the fact that recently we had a federal election in which calculations about economic matters were writ large and commitments to education were writ very small indeed. And a third is that this is the 25-year anniversary of the Karmel report Schools in Australia (1973), and the occasion has brought on a wave of nostalgia and reassessments about values and directions in education, both then and now. So the full title of my talk is 'Of deficits and other dangerous things ...' (The echoing in tone of the passage from Through the looking glass is also intentional, and the significance of this 1 hope will be apparent in the final part of my talk.)

My address has three main parts. In the first, paying homage to the current wave of neo-millennial reassessments and post, post-Karmel reflections, I try to reflect on research agendas, research paradigms, and how these are speaking to education today. More specifically, I want to look at those things we used to talk about in education as social inequalities, or disadvantages, and revisit a longstanding debate about whether or not we should think about these social differences as 'deficits'. In the second part of the talk, I want to talk about the conditions under which we now practice research, and especially about the effects of the financial deficits that occupy so much of the concerns of our employers, macro and micro, whether these be governments, universities, schools, departments, private bodies. What is happening to the way we are now doing research? In the final part of the talk I want to talk about the value and quality of educational research and especially the debate that has been raging in the UK (cf. Tooley \& Darby, 1998; to Ball \& Gewirtz, 1997; Hodkinson, 1998) about the deficits evident in much current educational research, especially qualitative research, a debate that is likely to take 
off here as the Australian Research Council and other bodies try to find new ways to assess whether they are getting value for money.

\section{RESEARCH PARADIGMS REVISITED: IS 'DEFICIT' A DIRTY WORD?}

The idea to talk on this theme initially came to me earlier in the year when I was measuring up to most people's expectations of what a 'real' educational researcher looks like - 1 was out in a school, doing fieldwork, as part of my longitudinal research, in The 12 to 18 project (Yates \& McLeod, 1996) and being funded by the Australian Research Council (ARC) to do it. I was sitting in a rather barren and very cold staffroom, with Julie McLeod, my fellow researcher, chatting to Keith McCallum, the teacher who had kindly added to his own already large workload by doing some of the school-based arrangements for our interviews. In the project, we have been following students at four schools since the beginning of secondary school and are interested in how they develop, what they think, what school effects can be discerned in this development, and where they end up. The students are now in Year 11, which, in Victoria, is for most people the beginning of their two-year final school certificate, the Victorian Certificate of Education (VCE). Keith was talking to us about the fact that in his school there is quite a drop-out in these final years and also that the numbers applying to do tertiary study have been decreasing in the last few years. One of the reasons for this, he thought, was nothing to do with major shifts in the optimism or pessimism of youth, or of a strategic assessment by them of what path would best further their chances of employment or success. Rather, it could be seen as a direct effect of some apparently minor changed bureaucratic processes. Previously, the applications and course selection materials were sent to schools, and at this school the students completed these in class. Now, students are required to go to a newsagent, and pay $\$ 10$ to buy the Victorian Tertiary Admissions Committee (VTAC) handbook, and then, if they want to apply for a course, they have to take another individual initiative and spend more time and money phoning in their choices on a premium rate phone line or on making a trip to a post office so they can pay $\$ 15$ and then lodge their preferences via the internet.

Shortly after this, as part of the same project, I was in another school, this time a wealthy private school, where students have the option of taking the International Baccalaureate rather than the VCE. One of the students was telling us what a good option this was, because if you scrape through it, with the barest pass (and he knew of no-one who had failed it), you would be slotted in to a Tertiary Entrance Rank (TER) of 78 - that is, in the top 22 per cent of students completing school. With a more average result in the International Baccalaureate (IB), you would be slotted into the top few percent of TER scores.

A bit later, I found myself talking to my sister. Lois is an information technology teacher, who teaches VCE in a school, but also teaches one evening VCE Tertiary and Further Education (TAFE) class. These are students who have previously dropped out of school and are returning to study in evening classes. In Lois's class, at the beginning of the year, one of the students didn't even know how to click a mouse, yet cost-cutting means that, compared with previous years, she can no longer take extra classes for such students when their CATS (common assessment tasks) are due for the VCE. A number of other schools in Victoria have had every student using their own lap-top since Year 7, students who would now be taking this same Year 12 subject.

Shortly after this again, I was at a research seminar where someone was reporting on findings from a major longitudinal database study that has been tracking students though and beyond school for some time. The researcher kept saying in this seminar that the finding arising from this major data-set was that 'socioeconomic status' accounted for only 2 per cent of post-school outcomes. It turned out when I queried the speaker, and also spoke further to other researchers associated with this project, that this was a somewhat technical interpretation of the results, and referred to the effect of SES net of other factors such as achievement at age 14, school attended, and so on.

So, where is all this leading in terms of social inequalities and the deficit issue?

1 began my own studies as an education researcher in the mid $70 \mathrm{~s}$, in the heyday of what was called 'new sociology of education'. One of the features of this movement, or research paradigm, was its rejection of what it called 'deficit' frameworks. We must stop explaining educational failure, it said, in terms of what students bring to school; we must start looking at it in terms of school's failure to appreciate and work with what the students bring. It's not, for example, that some kids do not speak properly; rather they speak 'non-standard English'. It's not that kids from non-English-speaking backgrounds or different races or ethnic groups have a handicap; rather they have access to different cultural histories and knowledges which the school curriculum has not capitalised on. It's not that girls or women in universities fail to measure up in certain ways; the problem is that we have been wrongly taking boys and men as the standard we work with and work to, and have not appreciated girls and their knowledge and their preferred learning and assessment styles. And so on.

The move from 'deficit' to what are often called 'inclusive' or 'affirmative' approaches to researching and reforming education institutions has led to a range of changes, especially in areas of curriculum, facilities and courses of study, many of them very positive indeed. To the extent these took place of course it has not been simply because some sociologists thought this was a good idea - it was because of social movements and social changes, and demands by groups themselves that they be given more attention. But the work of education researchers contributed directly and indirectly to some changes of policy and practice here, including a good deal of better treatment for large numbers of students.

But there are dangers in being locked into particular paradigms as a universal answer, and my sense is, as my earlier anecdotes were intended to illustrate, that in the present period the old-fashioned issue of 'disadvantage' is not being dealt with very well. I want to consider two further current examples, associated with different political camps and different research traditions (I will avoid labelling the 
political camps because I think it is quite inaccurate simply to see them as right and left, or conservative and radical).

First, consider researchers currently associated with the 'effective schools' movement, and framed by beliefs that most education problems will be overcome if we can sufficiently decentralise schools, free them up to be controlled and more fully financed by their local community, and allow greater operation of market choice on the part of the parent/consumer. The blindness of this approach to the different resources, financial, intellectual, cultural and entrepreneurial, of different families, communities and regions I find staggering. To give just one example when The Age in Melbourne ran a success story on a government school and a school council successfully taking advantage of the new conditions, it mentioned in passing that the School Council President found that he was able to draw on his experience as general manager of Melbourne Airport. For the school I referred to at the start of this study, whose students no longer were applying to tertiary institutions, the most elite old boy they can draw on is one who found fame and wealth as a footballer, but who has also been in trouble with the law.

What I am saying here is that in the rush to develop 'world's best practice', in the rush to win the prize for the largest single computer purchase by an Education Department anywhere in the world (Victoria, in case you haven't yet had the pleasure of being briefed on this fine achievement), in the rush to push 'analysis of variance' into infinity so that class shrinks down to a pinprick, something is being lost, and that something is some of the ordinary experiences and commonsenses and problems of those who are not at the cutting edge or who have to work with real disadvantages and deficits.

But let us also consider a second example, this time from a very different camp. This is the huge opposition there has been by certain researchers and by teacher unions in my state to state-wide testing. Now I happen to agree with the protesters that the testing may be a poor use of scarce educational funding and that it largely maps what classroom teachers know rather than giving diagnostic and other assistance to them, but I think it has been a misplaced strategy to make such a campaign of opposing the testing. The opposition to the state-wide testing in Victoria arose very much out of a tradition in which researchers and teachers do not want students and schools to be compared with each other or against a common standard, because they do not want anything other than a very positive picture to be given of what was happening in those schools or with those students. My concern is that many ordinary parents were tired of being given only 'affirmative', reassuring comments on their child's progress - they wanted some sense of the broader picture. Another concern is that, unless we publicise more fully the large disparities of achievement occurring from early in schooling, the issue of social inequalities remains hidden.

The points I am trying to make about educational inequalities and deficits are these (and, in passing, I want to say that these are not resolved simply by taking a more recent theoretical position, that of post-structuralist theory, and simply emphasising that we must query or deconstruct the categories and displace the binaries, though those approaches have made useful contributions to thinking about the education questions we deal with):

1. It is important that educational researchers go on assessing the context and effects of the paradigms they are following. The new teaching and learning practices and educational opportunities that attention to affirmative conceptions and decentralised control opened up in the optimistic and affluent 70s and 80s may be different from the effects those paradigms produce today.

2. Not all disadvantages are created equal: some differences are best thought of as differences, while others need to be thought about as disadvantages. In principle we can work towards forms of institution, and towards curriculum, teaching and assessment practices, that will be equally positive for females and males, or for students from different cultural backgrounds. But surely a different logic applies when we have to confront issues of wealth and know-how and cultural capital, and different histories of communities of schools of the kind illustrated in my earlier examples.

And of course this problem that I am talking about, the need to recognise and work with difference and treat it appropriately and affirmatively, alongside the need to recognise real disadvantages that should be system responsibilities, is nowhere more urgent and more difficult in finding good resolutions than in the case of Aboriginal education.

\section{FINANCIAL DEFICITS AND THE RESHAPING OF THE CONDITIONS OF EDUCATIONAL RESEARCH}

The last fifteen years have been an era of radical re-assessment of how education and educational research should be funded. Most education researchers I know now spend a good deal of every normal week engaged in discussion at their workplace about how to bring in more money, and also spend a good deal of each week burdening their nearest and dearest complaining about the stresses, overloads and difficulties of the work we have chosen to engage in. I'm not going to waste my time simply lamenting the fact that governments, private industry, wealthy benefactors and our universities haven't sufficiently recognised what worthy and valuable people we education researchers are, and haven't recognised how deserving we are of being paid at much higher rates and being rewarded in much finer ways than we are at present. But I do want to look at a couple of specific effects that I notice in this present era, an era where researchers seem less like explorers and inventors and diagnosticians, and more like beasts of burden, carrying a sort of magic deficit load (like a magic pudding) which, the more it is unloaded, the more it grows into new and heavier forms.

One specific effect of the new era that I personally have been very aware of is the need now to be doing research that costs money - and the more it can be seen to cost, the better. This is somewhat ironic in an era supposedly driven by a ubiquitous searching for economic efficiency. If employing as few people as possible is, regrettably, a sign of efficiency in industry and in schools, universities, hospitals, TAFE, we might ask why the reverse seems to apply when it comes 
to assessing the quality of researchers and, indeed, the quality of universities, on the basis of the size of their research grants. Similarly, if feminism has been so triumphant, we might wonder why we are in this area in particular so immersed in a 'mine is bigger than yours' type of competition.

One of the major contributions of feminism to educational research methodology to my mind was to ask us to look carefully at the relationships, the recognition, the effects and the silencing involved in how research got done. Some effects of the current ARC structures of recognition (both directly and because universities get indirect funding related to these) are:

- Research is seen as more important if I pay anyone else to go out and do some interviews or observations for me than if 1 do it myself.

- Research that involves flitting around the country, or, even better, lots of international meetings, is more important than research that involves working only at a local site.

- Empirical data gathering is valued over analytical, non-empirical, philosophical and other theoretical work. (In an earlier study of national databases I undertook with Gilah Leder and with some colleagues from ACER, it was very apparent that the government spends much more money on the gathering of data than on paying for good, or indeed any, analyses of the data - and indeed a lot remains unanalysed as a result) (Yates \& Leder, 1996).

Please note, I am not critical of large-scale work, nor of international collaboration and comparison - I think these are essential, and I engage in quite a bit of it myself. On the AARE Executive this year one of our concerns has been to forge closer links with research associations in other countries, to facilitate better international collaboration and attention to global developments. But I am critical of the way we are being driven by economic necessity to favour certain methodologies and sites over other methodologies that might also distinctively contribute to our understanding of local issues, grounded contexts, processes and nuances.

Of course the competitive ARC grants are not the only funding sources, and the university research hierarchy is not the only significant condition affecting Australian education researchers. Increasingly important too are consultancies and commissioned research. But this raises other issues about the reshaping of the educational research field.

In the current debate about educational research in England, which I'll talk more about shortly, one of the charges being made is that much educational research is grossly partisan. In the case of consultancies and commissioned research, it is not a new development for governments or industry bodies to give contracts to researchers whose values they share. This is certainly not a practice that is peculiar to only one political party when in government: the Karmel report was a child of that era, just as The self-managing school (Caldwell \& Spinks, 1988) is of this one But because it is now more urgent for all institutions to win higher numbers of consultancies, to bring in money for their continued existence, the issue of how successfully they can be seen to display the values of the commissioning body is given greater weight and weighs more heavily as an ongoing issue for researchers and faculties and institutions than it did previously. At the same time, both inside and outside universities, I think there has been a severe narrowing of tolerance for critical debate. The distinction between research and public relations has weakened and in some cases appears to be non-existent.

\section{IS CURRENT EDUCATIONAL RESEARCH DEFICIENT?}

In an age in which education spending has been so dominated by quality assessment and accountability exercises, it is not surprising that there is an emerging debate about educational research. Though 'globalisation' is treated as a new buzz word, Australian education has had a long, long history of looking to what other countries are doing and copying those debates and policies in some form. So I want to begin this final section of my talk by referring to the recen debates in the UK about the quality of education research, fairly confident that this issue will be soon striking Australian newspaper editors, politicians and university vice-chancellors as a topic that really needs to be looked at.

In the UK, the Professor of Education at Cambridge, David Hargreaves, publicly criticised educational research for being poor value for money, remote from educational practice, and often of indifferent quality. Following that, OFSTED, the UK Office for Standards in Education, commissioned a report by James Tooley (1998), which undertook an assessment of the research articles being published by UK researchers in the four leading British educational research journals. The report did not find support for Hargreaves' claim that research was failing to deal with issues relevant to practitioners, but did argue that a disturbing proportion of the articles showed flaws in methodology and presentation, particularly of 'partisanship' and of methodological inadequacy, and also evidence of lack of systematic replication and building of the research relative to previous research. Both in the press and in professional journals and newsletters, these claims have been publicised and rejoinders and further debates mounted. Many qualitative researchers in particular have claimed, with some justice, that Tooley imported criteria for judging the adequacy of a research account that were methodologically inappropriate to interpretive studies. Others have queried why the judgement of Tooley and his co-researcher, Doug Darby, should be accepted on articles outside their particular sphere of expertise, when the articles reviewed had already been assessed and passed by two referees of academic professional standing who did have expertise on the field of the article in question. Clearly, a talk like this is not a place where I can review the debate in any detail, but I do think the debate raises important issues about our field and about what criteria educational research should measure up to, and how it should be judged.

Education research encompasses many different activities: partnership and action research; consultancies of various kinds; evaluative research; 'basic' research on learning or teaching; cultural, contextual and policy studies; research on new technologies and new areas of knowledge. The main points I would like to make about the field are these (these are certainly not new points, but I consider they are points that need to be restated loudly today: Yates, $1997^{3}$ ): 
- What is 'useful' research can be measured in more than one way. It is common to interpret this as research that takes up problems that teachers or policy makers or institutions have, and results in an approach or findings they can act on. But research that identifies problems with approaches that are the current enthusiasm and that challenges them; or research that produces new ways of thinking about and seeing issues; or research that tests models of learning or teaching or organisation in some way; or research that engages with major discussions going on in disciplines outside education can also be useful.

- Education is a field of practice, or practices, and practices are located in different places, cultures, historical periods. In relation to calls for research to be more cumulative, we have to recognise that we are not dealing with a static phenomenon or object of study, and that 'findings' from one place or point in time may not be replicated in others (and the effects of single-sex versus coeducation is an excellent case in point).

- Education is a complex field. Although it is appropriate that some research be attempting to pin down and refine theories and explanations, a great many of its questions cannot replicate scientific or medical experiments with isolated variables and neat controls and double blinds, and must simultaneously deal with a complex web of actors, meanings, institutional histories, and psychological, epistemological and cultural questions.

In other words, education is a field located in change, where students and institutions are not eternally the same, where new practices have to be tried out, where there is a role for new ideas and visions, as well as testing and refining previous theories and findings about how particular processes of teaching, learning and organisation work.

I want now to return to the UK debate and make a couple of points about Tooley's and Hargreaves' criticisms. My first point is to encourage us not to dismiss debates about the adequacy of a piece of research or of a whole line of research as illegitimate. It is important that, inside as well as outside a research paradigm, we find ways of continuing to ask questions about whether the research is adequate to its questions and its purposes, or we are in danger of being seen as having nothing to offer other than our political values. I do think with qualitative research interpretive claims are often made with too little attempt to justify their adequacy or their limitations.

In this talk, for example, I have been using a lot of anecdotes and examples, and it is appropriate to question what weight these various examples should be given In such a discussion, I would argue that people who want to dismiss such anecdotal points out of hand, and to refer only to very controlled and large-scale studies, miss the point of researching a social phenomenon. I started off as a historian, and I would take the historian's position that observations, examples and anecdotes such as I began with are all legitimate evidence - but we need to go on further to discuss the meaning and weight to be given to such evidence. That is, I would also argue that qualitative researchers who feel that all they have to do is report an incident that suits their case and the case is proved should be challenged. We do need to pay more attention to evidence and its relationship to arguments and claims.
The same point certainly applies to many quantitative studies, which publicise findings using words that have everyday meanings, and that go well beyond what the study showed. The case of the claims about socioeconomic status (SES) and education I mentioned earlier is a case in point; as was some earlier work I did with Gilah Leder and colleagues from ACER on the Student Pathways Project. In that project we looked at a range of national databases and identified some of the misleading impressions we might get by simply working with their some of the as 'disability' or non-English-speaking simply working with their categories such (Yates \& Lity' or non-English-speaking background ('NESB') taken at face value (Yates \& Leder, 1996). So my first point is that we should be challenging each
other about our evidence and our claims.

My second point is that at the heart of Tooley's criticisms is an assumed model of what research is that has been widely and appropriately criticised across a large range of disciplines in the last two decades. It is a model that treats across a large if it can isolate a variable to be tested, institute adequate study, or by 'triangulation') consider all possible adequate controls (either in the as to why the conclusion advance explanations, and provide a case appropriate that some research appropriate that some research, even in education, should try to approximate to this form, but much of the time, whatever level we are addressing in our research problems - the teacher, the public, the students, policy makers - the research problem is located in complexity, has moral dimensions and requires judgement
and not just observation or measurement.

Some comments Richard Pring made recently in relation to teacher training 1 think are also relevant in thinking about what kind of activity we are engaged in as
education researchers:

[the knowledge required by teachers] is neither the purely theoretical knowledge developed and expounded through foundation disciplines, nor the purely practical knowledge in lists of competencies that can be acquired simply from doing. It is much more the kind of practical wisdom borne of deliberation, shaped by critical discussion in the context of the practical, informed by relevant theoretical perspectives which, however, by themselves, entail no one set of practices. It is more like mich, however, by themselves, than it is like moral preses. It is more like moral or political deliberation know-how includes the refined through critical tacit knowledge of the experienced teacher, but is refined through critical scrutiny in the light of alternative viewpoints ... acquired and constructed through the deliberations and criticism which require a special kind of community. (Pring, 1998) So, finally, what kind of community are we as educational researchers, and what
kind of community should we be?

I've been conscious since I embarked on my themes for this talk that it might many of my colleagues (and an inspirational vision for you, that I'm doing what many of my colleagues (and certainly my children) think I always do - inject an air want to say in ther some criticism, make some piecemeal comments. However, I want to say in this conclusion, in my defence, that lurking underneath all this I do have a vision for educational research that I feel quite passionately about, that I try 
to promote, and that I want to defend. It is a vision about what can be built and not just about what can be criticised; about democratic communities and relationships and voices within these.

When I undertook my own PhD some time ago, I subtitled it 'a discussion'. Since then, metaphors about discussions and conversations have been breaking out all over. Jane Roland Martin (1985) entitled her book on women philosophers in education Reclaiming a conversation. Social theorists, including Habermas, Beck, Giddens, Lash, Sandra Harding and others have also been somewhat preoccupied that one of the central problems of the modern social order is that of how people of different backgrounds can engage with each other and also with the type of scientific, technological and global issues facing the world at the end of the twentieth century. Not only do we have people of very different political values, and people widely differentiated in knowledge and power by their history, the colour of their skin, their sex, their physical appearance, but we have a knowledge explosion to an extent where a number of eminent social theorists would argue that we are faced with an ongoing complexity and uncertainty that is not resolvable by faith in any one expert system or answer (Beck et al., 1994).

I left my original discipline of history to pursue a career in educational research because I was interested in two broad issues that I still think matter, and that I still see as central ones for us: issues of what knowledge is important for young people today, and how this can be appropriately developed in education; and issues of what education is doing or might do in furthering or mitigating social inequalities. The style of research I do, though I try to be rigorous, is more like the Walrus's 'talking of many things' than the type of work that gets dignified with the title X's 'theory', or 'Y's findings'. It's like a more modest (but, I hope, tough) contribution to a conversation, like a 'speaking back to', or 'thinking about' or 'debating' or 'discussing where we are going and why'.

I don't think that everyone should be doing the same sort of work that I do; indeed I think it is really important that as education researchers we not all be working with the same interests and assumptions and methods. But I do think that the broad metaphor of being engaged in a discussion that needs to encompass more than one perspective is important and one that I do not want to see undermined. I am worried about the fact that university education faculties are being diminished, both in size and in range. The ranks and contributions of historians, philosophers, even sociologists, are thinning. And I'm concerned about the fact that there seem to be fewer and fewer times now when researchers of different paradigmatic persuasions talk to each other.

Inherent in this concern is a second belief - that although educational research is inevitably political, inherently moral and value-laden, it should not be totally reducible to politics. That is, that there should be space for ongoing discussion about the quality, the methodology, the rigour, the fairness, the effects of the different research we do, as there is in this conference. And we also want, through the quality and cogency of our research, to have people outside education, the public, those who work in education, vice-chancellors and politicians, to have respect for the research we do. This is not an easy time to be an educational researcher and it is impressive that in these circumstances, and on a world scale, so much good research is being done in Australia. When I am in other countries, I am constantly reminded of just how good recent Australian education research is am its quality, in its extent, and in its impaod recent Australian education research is - in some of the changes that in its impact. My hopes are that we can begin to arrest that we can retain that are narrowing and reducing the work that is being done entark of educational research as being persuade others to beling conversation with others; and that we can believe and persuade others to believe that the activity of doing good educational research is
something that matters.

\section{NOTES}

1 In that $i t$ has been a factor in changing the type of research 1 am currently doing 1 discussed this further in an earlier conference paper. See Yates (1995).

The ARC has

The ARC has recently commissioned a consultancy on the impact of education research, as part of its own reassessments.

1 am also aware that the position I outline is contested by developments associated with
deconstructive theorising

\section{REFERENCES}

Ball, S. J., \& Gewirtz, S. (1997). Is research possible? A rejoinder to Tooley's 'On school choice and

social class'. British Journal of Sociology of Education, I8(4), 575-586.
Beck, U., Giddens, A., \& Lash, S. (1994). Refexive modernization: Politic, tradiu the modern social order. Stanford CA. Refexive madernization: Politics, tradition and aesthetics in Caldwell, B. \& Spinks, J. (1988). The self-managing school. London. F.

Carroll, L. (1980 [1872]). The . The self-managing school. London: Falmer Press. found there. London: Macmillan \& $\mathrm{C}_{0}$. carpenter. In Through the looking glass and what Alice found there. London: Macmillan \& $\mathrm{Co}_{\text {. }}$ Hodkinson, P. (1998). Naivete and bias in educational research: The Tooley report. Research
Intelligence, 65, 16-17.

Karmel, P. H. (1973). Schools in Australia: Report of the Interim Conmittee for the Australian Schools Commission. Canberra, ACT: Australian Government Publishing Service. Martin, J. R. (1985). Reclaiming a conversation: The ideal of the educated woman. New Haven, CT:
Yale University Press.

Pring, R. (1998, August). Universities and teacher education. Address to British Educational Research
Association Conference.

Education. Educational research: A critique. London: Office for Standards in Yates, L. (1995, December). Just what sort of endeavour is policy research in education? Paper
presented at AARE Conference, Hobart.

Yates, L. (1997). Research methodology, education, and theoretical fashions: Constructing a Education, $10(4), 487-498$ era of deconstruction. International Journal of Qualitative Studies in

Yates, L., \& Leder, G. C. (1996). Student pathways: A review and overview of national databases on
gender equity. Canberra ACT: ACT Dept gender equity. Canberra, ACT: ACT Dept of Education \& Training.

Yates, L., \& McLeod, J. (1996). And how would your describe yourself? Researchers and researched in 88-103. 


\section{University Library}

\section{- M M I N E R VA A gateway to Melbourne's research publications}

Minerva Access is the Institutional Repository of The University of Melbourne

Author/s:

YATES, L

Title:

Of deficits and other dangerous things...

Date:

2010

Citation:

YATES, L. (2010). Of deficits and other dangerous things.... Gale, T (Ed.). Lingard, B (Ed.). Educational Research by Association, (1), pp.135-145. Sense Publishers.

Persistent Link:

http://hdl.handle.net/11343/31415 